\title{
ORAL HEALTH IN PATIENTS WITH LIVER DISEASES
}

\author{
Vladimir Panov*, Assya Krasteva** \\ * Department of Conservative dentistry and Pedodontics, Faculty of Dental \\ Medicine, Medical University, Varna, Bulgaria \\ ** Department of Oral Imaging and Oral Diagnostic, Faculty of Dental \\ Medicine, Medical University, Sofia, Bulgaria
}

\section{SUMMARY:}

In most of the patients with chronic hepatitis B and $\mathrm{C}$, the disease progression to liver cirrhosis and a liver transplantation is necessary.

Untreated oral diseases (including dental problems) can lead to infections and sepsis and may cause many complications in transplanted patients and a prerequisite dental evaluation is usually recommended for potential organ transplant candidates.

Our aim was to determine the dental status in patients with chronic liver disease, knowing that liver transplant will be a life choices.

Key words: dental status, liver disease, future transplantation, oral health;

\section{INTRODUCTION}

Hepatitis B and C are potentially life-threatening liver infections caused by the hepatitis $\mathrm{B}$ and $\mathrm{C}$ virus. It is a major health problem, as some of the patients with hepatitis $\mathrm{C}$ infection progress to cirrhosis (5).

It is considered that more than any other profession, dental practitioners and dental staff are involved in transmitting hepatitis virus $\mathrm{B}$ or $\mathrm{C}$ to their patients.

In most of the patients with chronic hepatitis B and $\mathrm{C}$, because of disease progression to liver cirrhosis, a liver transplantation is necessary.

Untreated oral diseases (including dental problems) can lead to infections and sepsis and may cause many complications in transplanted patients $(2,4)$.

In the literature bacterial sepsis is the most common

Table 1. Demographic data of the studied individuals cause of deaths, after transplantation, occurring during the first postoperative months and the risk of infection also increased by the over-immunosuppression of these patients. A potential source of infection may be dental foci (1)

Regarding these problems, patients being prepared for liver transplantation should be evaluated for their dental health. $(2,4)$, to avoid and reduce adverse complications after transplantation.

AIM: Our aim was to determine the dental status in patients with chronic liver disease, knowing that liver transplant will be a life choices.

\section{MATERIAL AND METHODS:}

25 patients with chronic hepatitis $\mathrm{B}$ and $\mathrm{C}$ and cirrhosis were included in the study. Patients were recruited from the Clinic of Gastroenterology "Sveti Ivan Rilski", Medical University, Sofia. As controls were used 71 disease free subjects (without any liver disease).

Oral examinations for the presence of gingivitis (assessed by Papilla bleeding index - PBI), dental caries, edentulism, and dental hygiene (using debris index - DI and calculus index -CI assessed by Green и Vermillion index), were performed prospectively in patients with chronic liver disease and controls.

\section{RESULTS AND DISCUSSUION}

The demographic and medical characteristics of the studied individuals are given in Table 1. Results from the oral health status (dental status, oral hygiene status and papilla bleeding are present in Tabl 2 and Tabl 3.

\begin{tabular}{|l|cc|c|}
\hline Groups & \multicolumn{2}{|c|}{ Sex (Nr) } & Age (yrs) \\
& males & females & median and range \\
\hline Hepatitisand cirrhosis & 13 & 12 & 55,3 \\
& & & $(24-87)$ \\
\hline Healthy & 47 & 49 & $\begin{array}{c}43,6 \\
(18-87)\end{array}$ \\
\hline
\end{tabular}


Table 2. Oral health status in patients with liver diseases and controls. Results are expressed by mean and standard deviation; number of a studied individuals is given in parenthesis.

\begin{tabular}{|l|c|c|c|c|c|c|}
\hline $\mathbf{X}$ & Caries & Extraction & DI & CI & OHI & PBI \\
\hline Sd & & & & & & \\
\hline Hepatitisand cirrhosis & 1,26 & 9,80 & 1,58 & 1,18 & 2,7 & 2,53 \\
$(\mathbf{2 5 )}$ & $\pm 3,8$ & $\pm 9,2$ & $\pm 0,7$ & $\pm 0,8$ & $\pm 1,5$ & $\pm 0,9$ \\
\hline Healthy & 0,94 & 3,01 & 1,09 & 0,49 & 1,53 & 1,95 \\
(71) & $\pm 1,3$ & $\pm 5,4$ & $\pm 0,7$ & $\pm 0,7$ & $\pm 1,2$ & $\pm 0,9$ \\
\hline
\end{tabular}

Table 3. Oral health status in patients with liver diseases and controls. Results are expressed by median and range; number of a studied individuals is given in parenthesis.

\begin{tabular}{|l|c|c|c|c|c|c|}
\hline $\begin{array}{l}\text { M } \\
\text { (range) }\end{array}$ & Caries & Extration & DI & CI & OHI & PBI \\
\hline Hepatitisand cirrhosis & 0 & 7 & 2 & 1,25 & 3,05 & 3 \\
(25) & $(0-16)$ & $(0-32)$ & $(0-2,2)$ & $(0-3)$ & $(0-5)$ & $(0-4)$ \\
\hline Healthy & 0 & 1 & 1 & 0,16 & 1,3 & 2 \\
$(\mathbf{7 1 )}$ & $(0-6)$ & $(0-28)$ & $(0-3)$ & $(0-3)$ & $(0-6)$ & $(0,5-4)$ \\
\hline
\end{tabular}

E. A. Coates et coworkers in patients with hepatitis registered that the number of decayed and missing teeth was greater for all patients aged between 25 and 50 years. The authors didn't find the significant difference in CPITN for studied patients and controls, but poor periodontal health was noted for those individuals with hepatitis C (3).

We found similar changes concerning the number of extracted and caries-affected teeth at approximately the same age of patients. The average in control group for missing teeth was 3,01 $\pm 5,42$, compared to those in patients $9,80 \pm$ 9,21 (Table 2). The median values were also differ between patients and healthy ( 1 versus 7 ) (Table 3 ). more then 6 extractions had $35 \%$ of the patient. Almost equally were the patients with 2 to 4 and 4 to 6 missing teeth.

Comparing to the date from $2000 \mathrm{~J}$ Guggenheimer et coworkers mention that edentulism rate for liver transplant candidates aged 50-69 year was significantly greater than national rates (4). These results indirectly indicate the neglect dental health of these patients.

Concerning dental caries we registered decayed teeth in $21 \%$ of the hepatitis patients, while there is one study with $67 \%$ affected patients (2). Our percentage we explain with elevated edentulism rate (Tabl 2).

The average of dental caries was higher in this group $(1,26 \pm 3,827$ compared to the controls $0,94 \pm 1$, $)$ (Tabl 2). We observed in one patient 16 decayed teeth. For comparison in control subjects one patients had 6 dental caries, which reflects in the range (Tabl 3).

About the presence of dental plaque the average of DI was 1,58 in hepatitis group, compared to 1 in controls (Tabl 2). Only $15 \%$ of the patients had value until 1 , which is similar to the date of P. Barbero et coworkers. They observed in $85 \%$ of patients with hepatitis poor oral hygiene, in $45 \%$ periodontitis and in $15 \%$ gingivitis catarrhalis ( $\mathrm{P}$. Barbero, 1996).

The average value of calculus index in hepatitis group was 1,18 and reflect that the majority of patients had subgingival calculus. In controls we detected the average value of calculus index 0,49 (Tabl. 2).

Some authors reported the same as our findings. Measures of oral hygiene, dental care, and periodontal parameters were worse and the number of teeth requiring treatment was higher in hepatitis patients with or or without cirrhosis than in healthy subjects $(1,2,6)$.

Regarding the results from Papilla bleeding index the average in hepatitis patients was 2,53, median was 3, compared to the value in controls - average 1,95 and median -2 . These values correspond to the moderate gingivitis in hepatitis group.

In our hepatitis patients elevated value of PBI, DI and $\mathrm{CI}$, the presence of decayed teeth and increased edentulism rate objectively reflect the poor and neglected oral health . The same conclusion was mention by J Guggenheimer et coworkere, which established that the presence of 2 or more carious teeth and/or 2 or more teeth that were mobile due to periodontal disease were indicators of severe dental disease as well as neglect of oral health (4).

\section{CONCLUSION:}

Patients with chronic hepatitis have poor oral health resulting not only the large number of extracted teeth, caries lesions, but also and a presence of dental plaque and 
calculus and gingival bleeding. That means that the patients with hepatitis have significant oral health needs.

The monitoring of oral health by dentists before transplantation and the achievement of specific protocols of prophylaxis are helpful in the prevention of complications after transplantation in these patients.

These facts again pose the question of the place of dentists in the global medicine, especially their principal role not only in oral health, but also in successful liver transplantation.

\section{REFERENCES:}

1. Anand A., Pardal P, Sachdev V. Dental caries and periodontal disorders in chronic liver disease. Medical Journal Armed Forces India. 2001 Jan;57(1):26-30.

2. Barbero P, Garzino Demo MG, Milanesio M, Ottobrelli A. The dental assessment of the patient waiting for a liver transplant. Minerva Stomatol. 1996 Oct;45(10):431-439. (Article in Italian) [PubMed]
3. Coates EA, Brennan D, Logan RM, Goss AN, Scopacasa B, Spencer AJ, et al. Hepatitis $\mathrm{C}$ infection and associated oral health problems. Aust Dent J, 2000 Jun;45(10):108-114. [PubMed] [CrossRef]

4. Guggenheimer J, Eghtesad B, Close JM, Shay C, Fung JJ. Dental health status of liver transplant candidates. Liver Transpl. 2007 Feb;13(2):280-286. [PubMed] [CrossRef]
5. Krastev Z., A. Kisselova, R. Kolarov. In: Oral medicine, I. Sapunjiev EOOD, Sofia, 340-350 (in Bulgarian).

6. Novacek G, Plachetzky U, Potzi R, Lentner S, Slavicek R, Gangl A, Ferenci P. Dental and periodontal disease in patients with cirrhosis - role of etiology of liver disease. J Hepatol. 1995 May;22(5):576582. [PubMed]

\section{Address for correspondence:}

Dr. Vladimir Panov

Faculty of Dental Medicine, Medical University, Varna 150, Tzar Osvoboditel Str., office 623, 9000 Varna, Bulgaria E-mail: vl_panov@abv.bg 